\section{Predisposing Factors for Traumatic Dental Injury in Primary Teeth and Seeking of Post-trauma Care}

Maria Betânia Lins Dantas Siqueira1, Monalisa Cesarino Gomes', Ana Cristina Oliveira2, Carolina Castro Martins², Ana Flávia Granville-Garcia1, Saul Martins Paiva ${ }^{2}$
'Graduate Program in Dentistry, UEPB - State University of Paraiba, Campina Grande, PB, Brazil

${ }^{2}$ Department of Pediatric and Orthodontic Dentistry, UFMG Federal University of Minas Gerais, Belo Horizonte, MG, Brazil

Correspondence: Prof. Dr. Saul Martins Paiva, Avenida Bandeirantes, 2275/500, 30210-420 Belo Horizonte, MG, Brasil. Tel.: +55-31-3409-2470. e-mail: smpaiva@uol.com.br
The aim of the present study was to investigate predisposing factors for traumatic dental injury (TDI) in the primary dentition and seeking of dental care after the occurrence of TDI. A randomized population-based cross-sectional study was carried out with 814 children aged 3 to 5 years enrolled at public and private preschools in the city of Campina Grande, PB, Brazil. Parents were asked to fill out a questionnaire on demographic data and the child's history of TDI. TDI was evaluated by clinical examinations performed by three previously calibrated dentists (Kappa: 0.85 to 0.90). Bivariate and multivariate Poisson regression models were constructed for TDI and the parent-reported search for dental care $(\alpha=0.05)$. The prevalence of TDI was $34.6 \%$. The most common type of TDI was enamel fracture (55.0\%). The central incisors were the most frequently affected teeth (87.5\%). Predictors for TDI in the primary dentition were household income $>$ U \$312.50 (PR: 1.355; 95\% Cl: 1.050-1.724) and overjet >2 mm (PR: 1.539; 95\% Cl: 1.219-1.942). The predictor for seeking dental care following TDI was parent's age >30 years (PR: 1.753; $95 \% \mathrm{Cl}: 1.039-2.960)$. Household income and overjet were associated with TDI. Among children having suffered TDI, parent's age is a crucial determinant for seeking dental care.
Key Words: tooth injuries, risk factors, primary teeth, dental care, traumatic dental injuries.

\section{Introduction}

Traumatic dental injury (TDI) is a frequent occurrence among preschool children, especially those at an early age. In this period, children have imprecise movements, poor balance and slow reflexes and are therefore more susceptible to falls while learning to stand, walk and run (1). TDI is the second most prevalent type of adverse dental condition among children and is considered a public health problem due to its high prevalence rate (25.6\%-62.1\%), expensive treatment cost and long-term consequences to oral health, including extensive treatment throughout the patient's life (1-4).

Accentuated overjet and inadequate lip coverage are considered factors associated with TDI in children $(1,2)$. However, the association between TDI and environmental determinants (socioeconomic indicators) and/or human behavior (nutritional status) remains unclear $(2,3,5,6)$.

TDI can cause pain, have permanent esthetic and functional impacts, disturb the development of the permanent successors and exert a negative psychological effect on both children and parents (7). This event is usually sudden, unexpected and accidental and often requires dental care (8). In general, laypersons are unaware of the risks of trauma and possible harm to the primary and permanent dentition or what can be done to avoid such situations (7). Failure to seek treatment following the occurrence of TDI has also been reported (5). Some of the reasons for this include the temporary nature of primary teeth, the fact that dental trauma is not considered a disease and limited access to the dental care system, especially among lower income groups (5). However, there is a gap in the literature regarding the investigation of factors associated with the failure to seek treatment for trauma to the primary dentition. While a more in-depth exploration of this issue has recently been performed (3), the investigation was not a randomized, population-based study.

The aim of the present study was to determine factors associated with TDI in the primary dentition and the subsequent search for dental care.

\section{Material and Methods Sample Characteristics}

A randomized, population-based, cross-sectional study was carried out with 814 children (422 males and 392 females) aged 3 to 5 years enrolled at public and private preschools in the city of Campina Grande, PB, Brazil. The participants were chosen from a total population of 12,705 children in this age group and corresponded to $6.41 \%$ of this population. Campina Grande (population 386,000 ) is an industrialized city in Northeastern Brazil divided into 
six health districts. The city has considerable cultural, social and economic disparities, with a mean monthly income of US\$110 per capita and a Human Development Index of 0.72 (9).

A two-phase random sampling strategy was used to ensure representativity. Preschools were randomly selected from each health district in the first phase and children were randomly selected from each preschool in the second phase. Eighteen of the 127 public preschools and 15 of the 122 private preschools in the city of Campina Grande were randomly selected. The sample size was calculated based on a $4 \%$ margin of error, a 95\% confidence level and a $50.0 \%$ prevalence rate of TDI. As multi-stage sampling was employed, a correction factor of 1.2 was applied to increase the precision, leading to a minimum sample size of 720 schoolchildren. A further $20 \%$ was added to compensate for possible losses, resulting in a total sample of 864 schoolchildren.

This study was approved by the Ethics Committee of the State University of Paraiba, Brazil. All parents/ guardians received information regarding the objectives and signed a statement of informed consent.

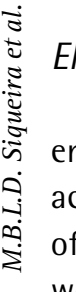
were having four missing maxillary incisors due to caries or physiological exfoliation, which could compromise the clinical diagnosis of TDI and refusal to be examined (noncooperative behavior).

\section{Training and Calibration Exercise} The theoretical step involved a discussion of the criteria for the diagnosis of TDI and an analysis of photographs. A specialist in pediatric dentistry (gold standard in this theoretical framework) coordinated this step. Three dentists examined 50 previously selected children between 3 to 5 years of age. Inter-examiner agreement was tested by comparing each examiner with the gold standard. A 7-day interval was established between clinical examinations for the determination of intra-examiner agreement. Cohen's Kappa values ranged from 0.88 to 0.90 for intra-examiner agreement and 0.85 to 0.90 for inter-examiner agreement.

\section{Pilot Study}

study was performed to test the methodology and understanding of the questionnaires. The children in the pilot study $(n=40)$ were not included in the main sample. As there were no misunderstandings regarding the questionnaire or the methodology, no changes needed to 


\section{Anthropometric Data}

Nutritional status was determined using the Anthroplus software program, which provides the body mass index (BMI) following the input of weight (kilograms), height (meters), date of birth and date of the clinical examination (15). Z scores were used to determine nutritional status. Children with $Z<-1$ for their height/weight ratio were considered malnourished/severely malnourished; children with a score ranging from $-1 \mathrm{SD} \leq \mathrm{Z} \leq+1 \mathrm{SD}$ for their height/ weight ratio were considered to be within the ideal range; and those with a score ranging from $+1 \mathrm{SD}<\mathrm{Z}>3 \mathrm{SD}$ for their height/weight were considered overweight/obese.

\section{Statistical Analysis}

Frequency distributions of the data were determined. The dependent variables were TDI and the search for dental care following TDI. Bivariate Poisson regression analysis with robust variance was employed to determine associations between the independent and dependent variables $(p<0.05)$. Forward stepwise multivariate Poisson regression models were constructed for variables with a $p$-value $<0.20$ in the bivariate analysis. Statistical analysis was performed with the aid of the Statistical Package for Social Sciences (SPSS for Windows, version 18.0, SPSS Inc, Chicago, IL, USA). Two models were constructed - one for the occurrence of TDI based on the clinical examination and another for parents/caregivers' reports of having sought dental care following the occurrence of TDI. Only children whose parents reported the occurrence of TDI were included in the latter model. The presence of TDI reported by parents/ caregivers (yes/no) was compared to TDI determined by clinical examination (yes/no).

\section{Results}

A total of 814 pairs of parents/children participated in the study, corresponding to $94.32 \%$ of the total determined by the sample calculation process. The loss of 50 children was due to removal from study due to medical reasons (2), incomplete questionnaire (15), absence from preschool on the days scheduled for the clinical examinations (15) and lack of cooperation during the clinical examination (18).

The prevalence of TDI was $34.6 \%$ and 376 teeth were affected. The maxillary central incisors were the most affected (87.5\%), followed by lateral central incisors (8.8\%). Only 14 affected teeth $(3.7 \%)$ were mandibular incisors. Enamel fracture was the most common type of TDI (55.0\%), followed by tooth discoloration (26.8\%), more than one trauma to same tooth (9.6\%), tooth avulsion (1.3\%), extrusive luxation (0.5\%) and intrusive luxation (0.5\%). Most children had only one tooth affected (62.9\%) (Table 1).

Table 2 displays the risk factors for TDI. In the bivariate analysis, a monthly household income $>U \$ 312.50$, dental caries on the incisors, overjet $>2 \mathrm{~mm}$ and absence of lip seal were associated to a greater occurrence of TDI $(p<0.05)$. The variables that remained in the multivariate Poisson model and were considered predictors for TDI were a monthly household income $>$ U\$ 312.50 (PR: $1.355 ; 95 \%$ $\mathrm{Cl}: 1.050-1.724)$ and overjet $>2 \mathrm{~mm}$ (PR: $1.539 ; 95 \% \mathrm{Cl}$ : 1.219-1.942).

Table 3 summarizes parents' reports regarding the children's history of TDI. As much as $27.8 \%$ of the children had suffered TDI. Among those with TDI, 36.5\% had suffered the injury at two years of age and $26.5 \%$ had suffered the injury up to the age of one year. Home was the most frequent place of occurrence $(77.5 \%)$ and falls constituted the most common cause (81.3\%). Only 46 parents (20.3\%) sought dental care after the occurrence of TDI.

Table 4 displays factors associated to seeking dental care after TDI among parents who perceived the trauma. In the bivariate analysis, parents older than 30 years sought dental care more frequently than those under 30 years of age. This variable remained in the multivariate Poisson model and was considered a predictor for seeking dental care following the occurrence of TDI (PR: $1.753 ; 95 \% \mathrm{Cl}$ : 1.039-2.960).

Table 1. Frequency distribution according to history of dental trauma, type of trauma and number of teeth affected in preschool children; Campina Grande, Brazil, 2012

\begin{tabular}{lcc}
\hline Variable & \multicolumn{2}{c}{ Frequency } \\
\cline { 2 - 3 } & $\mathrm{n}$ & $\%$ \\
\hline Trauma & 281 & 34.6 \\
Present & 533 & 65.4 \\
Absent & 814 & 100.0 \\
Total & & \\
Teeth affected & 329 & 87.5 \\
Maxillary central incisors & 33 & 8.8 \\
Maxillary lateral incisors & 14 & 3.7 \\
Mandibular incisors & & \\
Type of trauma (per tooth) & 204 & 55.0 \\
Enamel fracture & 25 & 6.7 \\
Enamel + dentin fracture & 0 & 0.0 \\
Complicated crown fracture & 2 & 0.5 \\
Extrusive luxation & 0 & 0.0 \\
Lateral luxation & 2 & 0.5 \\
Intrusive luxation & 5 & 1.3 \\
Avulsion & 100 & 26.8 \\
Tooth discoloration & 36 & 9.6 \\
More than one type of trauma & & \\
Number of teeth affected & & 62.9 \\
One & & 37.1 \\
Two or more & & \\
& & \\
\hline
\end{tabular}


Table 2. Frequency and Poisson regression analysis according to independent variables and occurrence of TDl in preschool children. Campina Grande, Brazil, 2012

\begin{tabular}{|c|c|c|c|c|c|c|}
\hline \multirow{3}{*}{ Variable } & \multicolumn{2}{|c|}{ TDI } & \multirow{2}{*}{\multicolumn{2}{|c|}{$\begin{array}{c}\text { Bivariate } \\
\text { Unadjusted prevalence ratio }\end{array}$}} & \multirow{2}{*}{\multicolumn{2}{|c|}{$\begin{array}{c}\text { Multivariate } \\
\text { Adjusted prevalence ratio }\end{array}$}} \\
\hline & \multirow{2}{*}{$\begin{array}{l}\text { Present } \\
\mathrm{n}(\%)\end{array}$} & \multirow{2}{*}{$\begin{array}{c}\text { Absent } \\
\mathrm{n}(\%)\end{array}$} & & & & \\
\hline & & & $p$-value ${ }^{(1)}$ & $(95 \% \mathrm{Cl})$ & $p$-value ${ }^{(1)}$ & $(95 \% \mathrm{Cl})$ \\
\hline \multicolumn{7}{|l|}{ Gender } \\
\hline Male & 155(36.7) & $267(63.3)$ & 0.170 & $1.143(0.944-1.383)$ & - & - \\
\hline Female & $126(32.1)$ & 266(67.9) & & 2352.indd 1.00 & - & - \\
\hline \multicolumn{7}{|l|}{ Age of child } \\
\hline 5 years & $85(32.4)$ & $177(67.6)$ & & 1.00 & - & - \\
\hline 4 years & $110(34.4)$ & $210(65.6)$ & 0.624 & $1.143(0.897-1.456)$ & - & - \\
\hline 3 years & $86(37.1)$ & $146(62.9)$ & 0.281 & $1.060(0.841-1.335)$ & - & - \\
\hline \multicolumn{7}{|l|}{ Age of mother } \\
\hline$\leq 30$ years & $134(32.5)$ & $278(67.5)$ & & 1.00 & - & - \\
\hline$>30$ years & $145(37.2)$ & $245(62.8)$ & 0.167 & $1.143(0.946-1.382)$ & - & - \\
\hline \multicolumn{7}{|c|}{ Mother's schooling (years) } \\
\hline$\leq 8$ years & 124(33.2) & $249(66.8)$ & & 1.00 & - & - \\
\hline$>8$ years & $156(37.5)$ & $281(64.3)$ & 0.565 & $1.074(0.887-1.300)$ & - & - \\
\hline \multicolumn{7}{|c|}{ Monthly household income } \\
\hline$\leq \mathrm{U} \$ 312.50$ & 138(33.2) & $278(66.8)$ & & 1.00 & & 1.00 \\
\hline$>\mathrm{U} \$ 312.50$ & $47(45.6)$ & $56(54.4)$ & 0.013 & $1.376(1.070-1.768)$ & 0.019 & $1.345(1.050-1.724)$ \\
\hline \multicolumn{7}{|c|}{$\mathrm{N}^{\circ}$ of persons living in home } \\
\hline$\geq 6$ & $39(31.7)$ & $84(68.3)$ & & 1.00 & - & - \\
\hline$<6$ & $235(34.9)$ & $439(65.1)$ & 0.505 & $1.100(0.832-1.454)$ & - & - \\
\hline \multicolumn{7}{|l|}{ Child's birth order } \\
\hline Middle & $33(33.7)$ & $65(66.3)$ & & 1.00 & - & - \\
\hline Oldest & $34(28.8)$ & $84(71.2)$ & 0.442 & $0.856(0.575-1.273)$ & - & - \\
\hline Youngest & $122(36.1)$ & 216(63.9) & 0.663 & $1.072(0.785-1.464)$ & - & - \\
\hline Only child & $91(35.5)$ & $165(64.5)$ & 0.743 & $1.056(0.764-1.458)$ & - & - \\
\hline \multicolumn{7}{|l|}{ Type of preschool } \\
\hline Private & $136(36.2)$ & $240(63.8)$ & 0.359 & $1.093(0.904-1.320)$ & - & - \\
\hline Public & $145(33.1)$ & 293(66.9) & & 1.00 & - & - \\
\hline \multicolumn{7}{|l|}{$\begin{array}{l}\text { Parent's perception of } \\
\text { child's oral health }\end{array}$} \\
\hline Poor & $14(25.9)$ & $40(74.1)$ & & 1.00 & - & - \\
\hline Good & $266(35.0)$ & $493(65.0)$ & 0.200 & $1.352(0.852-2.144)$ & - & - \\
\hline \multicolumn{7}{|l|}{ Dental caries on incisors } \\
\hline Yes & $109(30.7)$ & 246(69.3) & & 1.00 & - & - \\
\hline No & $172(37.5)$ & $287(62.5)$ & 0.046 & $1.220(1.003-1.485)$ & - & - \\
\hline \multicolumn{7}{|l|}{ Overjet } \\
\hline$\leq 2 \mathrm{~mm}$ & $145(28.0)$ & $372(72.0)$ & & 1.00 & & 1,00 \\
\hline$>2 \mathrm{~mm}$ & $130(46.6)$ & 149(53.4) & $<0.001$ & $1.661(1.378-2.002)$ & $<0.001$ & $1.539(1.219-1.942)$ \\
\hline \multicolumn{7}{|l|}{ Open bite } \\
\hline No & $208(33.3)$ & $417(66.7)$ & & 1.00 & - & - \\
\hline Yes & $72(40.9)$ & $104(59.1)$ & 0.053 & $1.229(0.997-1.516)$ & - & - \\
\hline \multicolumn{7}{|l|}{ Lip seal } \\
\hline Yes & 192(31.5) & $417(68.5)$ & & 1.00 & - & - \\
\hline No & $81(43.3)$ & 106(56.7) & 0.002 & $1.374(1.123-1.681)$ & - & - \\
\hline \multicolumn{7}{|l|}{ Nutritional status } \\
\hline Overweight/Obese & $76(31.9)$ & $162(68.1)$ & & 1.00 & - & - \\
\hline ldeal range & 190(36.5) & $331(63.5)$ & 0.231 & $1.142(0.919-1.419)$ & - & - \\
\hline $\begin{array}{l}\text { Malnutrition/Severe } \\
\text { malnutrition }\end{array}$ & $15(27.8)$ & $39(72.2)$ & 0.560 & $0.870(0.545-1.390)$ & - & - \\
\hline
\end{tabular}

¥Chi-square test with $\alpha$ set at 5.0\% *Variables incorporated into multivariate model: gender, age of child, monthly household income, age of mother, monthly household income, parent's perception of child's oral health, dental caries on incisors, overjet, open bite and lip seal. 


\section{Discussion}

Knowledge on trauma epidemiology in the primary dentition has been underexplored in comparison to the permanent dentition (4) and there is no consensus on the prevalence of TDI at this stage of life. In the present investigation, the prevalence rate was $34.6 \%$, which is in agreement with findings described in a number of Brazilian and international studies $(2,4,8,16)$, whereas other studies report lower rates $(1,17)$. The conflicting results may reflect different methodologies, patient selection methods, trauma classification indices, geographic characteristics, socioeconomic status and cultural/behavioral factors, which differ between countries (2).

The maxillary central incisors were the most affected teeth (87.5\%). Enamel fracture (55\%) and discoloration

Table 3. Frequency distribution according independent variables based on parents/caregivers' reports of TD1 in preschool children. Campina Grande, Brazil, 2012

\begin{tabular}{|c|c|c|}
\hline Variable & $\mathrm{n}$ & $\%$ \\
\hline \multicolumn{3}{|c|}{ History of dental trauma } \\
\hline Yes & 226 & 27.8 \\
\hline No & 588 & 72.2 \\
\hline \multicolumn{3}{|c|}{ Age at which trauma occurred } \\
\hline Up to 1 year & 56 & 26.5 \\
\hline 2 years & 77 & 36.5 \\
\hline 3 years & 49 & 23.2 \\
\hline 4 years & 22 & 10.5 \\
\hline 5 years & 7 & 3.3 \\
\hline \multicolumn{3}{|l|}{ Site of occurrence } \\
\hline Home & 175 & 77.5 \\
\hline Preschool & 17 & 7.5 \\
\hline Other & 31 & 13.7 \\
\hline Does not remember & 3 & 1.3 \\
\hline \multicolumn{3}{|l|}{ Cause of TDI } \\
\hline Fall & 183 & 81.3 \\
\hline Fight/Push & 24 & 10.7 \\
\hline Sports & 2 & 0.9 \\
\hline Car accident & 1 & 0.4 \\
\hline Other & 15 & 6.7 \\
\hline \multicolumn{3}{|c|}{ Search for dental care following trauma } \\
\hline Yes & 46 & 20.3 \\
\hline No & 180 & 79.7 \\
\hline
\end{tabular}

(26.8\%) were the most frequent manifestations and the majority of children had only one tooth with trauma (62.9\%). These results are in agreement with findings described in previous studies $(2,4,5)$. The greater number of traumas of lesser magnitude may be related to the environment in which the examinations were carried out, whereas studies conducted at hospitals generally report a higher frequency of dislocations (2).

No statistically significant difference between genders was found for the occurrence of TDI, likely because male and female children at the evaluated age range are exposed to the same risk factors $(3,4,5)$. Although there is a general consensus in the literature that there is an increased prevalence of age-TDI association, because of the cumulative nature of traumatic injuries $(2,4)$, TDI was not significantly associated with age in the present study. It should be stressed that age was recorded at the time of the data collection procedure based on parents' reports and was not recorded when the trauma occurred.

Mother's age was not a predictor of the presence of TDI. To the best of our knowledge, no study has evaluated the association between this variable and dental trauma. However, decision was made to perform this analysis based on the fact that older mothers often have more autonomy (18) and many work outside the home, delegating the responsibility of the child to caregivers.

Income was the only socioeconomic indicator that remained associated with TDI in the final model, which agrees with findings described in previous studies $(4,19)$. Children from families with a greater income have more access to sports and recreational equipment that offers greater risk of falls, such as bicycles and roller skates, making them more susceptible to TDI. While type of school was used as a socioeconomic indicator associated with TDI in a previous Brazilian study (2), no such association was found in the present study. This may be due to the fact that Brazil is currently experiencing an increase in income per capita (9) and it is possible that the type of school is no longer a suitable socioeconomic indicator. As children with a less favorable socioeconomic status may be found enrolled in private schools, the analysis of income may be the most accurate socioeconomic indicator for this population.

Birth order is another variable that has been underexplored in the literature on TDI. One might expect that older children in the family would have a higher frequency of dental trauma (20). However, this variable did not remain in the final model, suggesting that birth order exerts no influence on the occurrence of TDI.

No association was found between the perception of the child's oral health and TDI in the final model. It was expected that a greater number of injuries would be found in children whose parents had a negative perception 
regarding their child's oral health. However, this did not occur, probably due to the fact that most injuries were limited to the enamel and the fact that TDI is not a disease.

Although a sensitive measure for the diagnosis of dental caries was employed (ICDAS II) (14), no association was found between caries on the maxillary incisors and TDI.
Indeed, children without caries had a higher frequency of TDI in the final model. Previous studies employing a different measure for the diagnosis of caries (DMFT index) (12) also found no association between this variable and TDI (3). These findings are more likely due to the fact that, although caries weakens dental tissues, extrinsic factors

Table 4. Frequency distribution and Poisson regression analysis according to independent variables and dental care for TDI in preschool children. Campina Grande, Brazil, 2012

\begin{tabular}{|c|c|c|c|c|c|c|}
\hline \multirow{3}{*}{ Variable } & \multicolumn{2}{|c|}{ Dental care for TD1 } & \multirow{2}{*}{\multicolumn{2}{|c|}{$\frac{\text { Bivariate }}{\text { Unadjusted prevalence ratio }}$}} & \multirow{2}{*}{\multicolumn{2}{|c|}{$\frac{\text { Multivariate }}{\text { Adjusted prevalence ratio }}$}} \\
\hline & \multirow{2}{*}{$\begin{array}{l}\text { Yes } \\
\mathrm{n}(\%)\end{array}$} & \multirow{2}{*}{$\begin{array}{l}\text { No } \\
\mathrm{n}(\%)\end{array}$} & & & & \\
\hline & & & $p$-value $e^{(1)}$ & $(95 \% \mathrm{Cl})$ & $p$-value $e^{(1)}$ & $(95 \% \mathrm{Cl})$ \\
\hline \multicolumn{7}{|l|}{ Gender } \\
\hline Male & $26(20.1)$ & 103(79.9) & \multirow{2}{*}{0.932} & 1.00 & - & - \\
\hline Female & $20(20.6)$ & 77(79.4) & & $1.023(0.608-1.721)$ & - & - \\
\hline \multicolumn{7}{|l|}{ Age of mother } \\
\hline$\leq 30$ years & $19(14.8)$ & $109(85.2)$ & \multirow{2}{*}{0.029} & 1.00 & \multirow{2}{*}{0.036} & 1.00 \\
\hline$>30$ years & $26(33.8)$ & $51(66.2)$ & & $1.806(1.063-3.066)$ & & $1.753(1.039-2.960)$ \\
\hline \multicolumn{7}{|l|}{ Mother's schooling (years) } \\
\hline$\leq 8$ years & $19(16.8)$ & $94(83.2)$ & \multirow{2}{*}{0.190} & 1.00 & - & - \\
\hline$>8$ years & $27(23.9)$ & $86(76.1)$ & & $1.421(0.840-2.404)$ & - & - \\
\hline \multicolumn{7}{|l|}{ Monthly household income } \\
\hline$>$ U\$ 312.50 & $17(13.0)$ & $113(87.0)$ & \multirow{2}{*}{0.428} & 1.00 & - & - \\
\hline$\leq \mathrm{U} \$ 312.50$ & $2(7.4)$ & 25(92.6) & & $1.765(0.433-7.197)$ & - & - \\
\hline \multicolumn{7}{|c|}{ Number of people living at home } \\
\hline$<6$ & $36(19.20)$ & $151(80.8)$ & \multirow{2}{*}{0.390} & 1.00 & - & - \\
\hline$\geq 6$ & $8(23.5)$ & $26(76.5)$ & & $1.789(0.474-6.753)$ & - & - \\
\hline \multicolumn{7}{|l|}{$\begin{array}{l}\text { Parent's perception of } \\
\text { child's oral health }\end{array}$} \\
\hline Poor & $2(11.8)$ & 15(88.2) & \multirow{2}{*}{0.390} & 1.00 & - & - \\
\hline Good & $44(21.1)$ & 165(78.9) & & $1.789(0.474-6.753)$ & - & - \\
\hline \multicolumn{7}{|l|}{ TDI } \\
\hline Absent & 19(18.2) & 85(81.8) & - & 1.0 & - & - \\
\hline Discoloration & $10(34.1)$ & $22(65.9)$ & 0.108 & $1.711(0.888-3.294)$ & - & - \\
\hline Enamel fracture & $9(16.9)$ & $44(83.1)$ & 0.842 & $0.929(0.452-1.911)$ & - & - \\
\hline Enamel + dentin fracture & $5(20.0)$ & $20(80.0)$ & 0.841 & $.095(0.453-2.648)$ & - & - \\
\hline $\begin{array}{l}\text { Avulsion and }>1 \text { trauma } \\
\text { to same tooth }\end{array}$ & $3(25.0)$ & $9(75.0)$ & 0.562 & $1.368(0.474-3.954)$ & - & - \\
\hline \multicolumn{7}{|l|}{ Number of teeth with TDI } \\
\hline None & 19(18.3) & 85(81.7) & - & 1.00 & - & - \\
\hline One & $14(20.0)$ & $56(80.0)$ & 0.323 & $1.368(0.735-2.549)$ & - & - \\
\hline Two or more & $13(25.0)$ & $39(75.0)$ & 0.775 & $1.095(0.589-2.036)$ & - & - \\
\hline
\end{tabular}

${ }^{*}$ Chi-square test with $\alpha$ set at 5.0\%. ${ }^{*}$ Variables incorporated into multivariate model: mother's schooling, age of parent and TD1. 
contribute more effectively to TDI.

There is no consensus in the literature regarding the criterion for measurement of overjet in studies on dental trauma. In the present study, overjet equal to or greater than $2 \mathrm{~mm}$ was considered accentuated $(3,11)$ and was associated with TDI. This result agrees with findings described in previous studies $(2,3,5)$. In contrast, open bite and lip seal were not associated with TDI, which has also been reported elsewhere (3). There is no consensus on the association between TDI and either open bite or lip seal $(1-3,5,21)$. However it is important to note that authors discuss the importance of lip seal for TDI and reported that when children present earlier malocclusion but the lip seal is adequate, the TDI could be less frequent due to protection of the lip (21). It may be assumed that anterior earlier malocclusions diagnosed in this study, particularly overjet, were not so severe and therefore not always related to the lack of lip seal.

It has been shown that overweight children have poorer balance and are therefore more susceptible to TDI (22). However, no such association was found in the present study. Other studies were not unanimous with regards to this association $(2,6)$, which is possibly explained by the different age groups evaluated.

The prevalence of trauma perceived by parents was $27.8 \%$, which is lower than the rate determined by the clinical examination (34.6\%). Previous studies report similar findings $(3,5)$. According to a number of authors, the perception of TDI is directly related to the severity of the injury $(5,16)$. Thus, as the majority of injuries in the present study were mild, it is likely that the parents did not perceive them.

Based on parents' reports, TDI occurred with higher frequency in the first three years of life. In the literature, parents report the occurrence of TDI with higher frequency at ages of 1 and 2 years $(5,7)$ as well as two and four years $(3,23)$. This is a critical phase in which the permanent incisors are not yet completely mineralized and, consequently, sequelae of greater severity may occur as a result of trauma (17). Moreover, the age at which TDls occur is important for the establishment of strategies for predicting and preventing more serious consequences to the germ of the permanent successor (3).

Regarding the etiology and site of occurrence, falls and home were the most cited ( $81.3 \%$ and $77.5 \%$, respectively), which is consistent with the literature $(3,5,8)$. A possible explanation is the fact that children in the evaluated age group spend most of their time at home. Moreover, their underdeveloped motor skills and lack of a notion of danger may be contributing factors. Thus, parents and caregivers should be made aware of the need to provide closer supervision and offer safe environments for children in order to reduce the risk of TDI.

Factors associated with the search for treatment following the occurrence of TDI have been underexplored. In the present study, mothers aged 30 years or more sought treatment for their children more than those aged less than 30 years. Few studies are available in the literature reporting the age of parents/caregivers and the search for treatment, which hampers the comparison of the results. A number of authors state that older mothers tend to have greater autonomy, are more discerning and seek more the health services $(18,24)$. In contrast, other authors found no significant association between mother's age and the search for dental care for children for either routine care or specific treatment (25). Studies with a similar methodology stress the importance of socioeconomic factors, such as difficulties regarding access to services. In Brazil, child health has been on the public health policy agenda for decades. However, maternal-child health care actions have not reached universal coverage $(3,5,25)$. Another important aspect to consider is the fact that parents/caregivers tend to take children for treatment only in more severe cases of TDI (3), which could explain why the search for treatment in this study was low, as most children suffered mild TDI.

In the present study, most children did not receive any care following TDI. There is evidence that failure to seek treatment after TDI in primary teeth stems from a lack of importance given to this dentition $(3,5)$. Thus, parents/ caregivers must be instructed on the possible sequelae in both the traumatized tooth and its permanent successor. Since not all children in the evaluated age group are regularly enrolled at schools, a viable alternative may be educational campaigns through the Family Health Strategy. This is a Brazilian government's program in which health professionals and community health agents visit homes to offer guidance to low-income families regarding health problems. Moreover, there is a need to widen dental care coverage for this group and improve access to healthcare services.

The power of the present study, as demonstrated by its adequate sample size and the multivariate analysis employed, lends strength to the probability that the results observed did not occur by chance or due to the effect of confounding factors. The profile of TDI found in this investigation is consistent with those of previous studies. However, the goal the present study was to explore possible causes for the search for treatment following occurrence of the TDI, which is an important aspect for the design of educational programs with special attention to the the follow up of TDIs due to the possible long-term consequences.

The prevalence of TDI was high in the present study, with enamel fracture on the maxillary incisor appearing 
as the most frequent type of trauma. Household income and overjet were associated with TDI. Parents/caregivers aged 30 years or more were more likely to seek treatment for their children following TDI.

\section{Resumo}

0 objetivo do presente estudo foi avaliar os fatores predisponentes para o traumatismo dentário (TD) na dentição decídua e a procura por tratamento odontológico após a ocorrência do TD. Um estudo transversal de base populacional randomizado foi realizado com 814 crianças entre 3 e 5 anos de idade, matriculadas em pré-escolas públicas e privadas da cidade de Campina Grande, PB, Brasil. Um questionário foi preenchido pelos pais sobre dados sociodemográficos e histórico de TD da criança. TD foi avaliado através de exames clínicos realizados por três dentistas previamente calibrados (Kappa: 0,85-0,90). Modelos de regressão de Poisson bivariado e multivariado foram realizados para TD e a procura por tratamento odontológico após o TD $(\alpha=0.05)$. A prevalência de TD foi de $34,6 \%$. 0 tipo mais comum de TD foi a fratura de esmalte $(55,0 \%)$ e os incisivos centrais superiores foram os dentes mais acometidos $(87,5 \%)$. Preditores para o TD na dentição decídua foram renda familiar $>\mathrm{U} \$ 312.50$ (RP: 1,355; IC 95\%: 1,050-1,724) e overjet >2 mm (RP: 1,539; IC 95\%: 1,219-1,942). 0 fator preditor para a procura de tratamento odontológico após TD foi a idade dos pais $>30$ anos (RP: 1,753; IC 95\%: 1,039-2,960). Renda familiar e overjet foram associados com o TD. Entre as crianças que sofreram TD, a idade dos pais foi um determinante crucial para a procura de tratamento odontológico.

\section{Acknowledgements}

This study was supported by the State University of Paraiba, the Brazilian Ministry of Education's Federal Agency for Support and Evaluation of Graduate Education (CAPES), the Research Foundation of the State of Minas Gerais (FAPEMIG) and the National Council for Scientific and Technological Development (CNPQ), Brazil.

\section{References}

1. Norton $\mathrm{E}, \mathrm{O}$ 'Connell AC. Traumatic dental injuries and their association with malocclusion in the primary dentition of Irish children. Dent Traumatol 2012;28:81-86.

2. Granville-Garcia AF, de Menezes VA, de Lira PI. http://www.ncbi.nIm. nih.gov/pubmed/17073924Dental trauma and associated factors in Brazilian preschoolers. Dent Traumatol 2006;22:318-322.

3. Viegas CM, Scarpelli AC, Carvalho AC, Ferreira FM, Pordeus IA, Paiva SM. Predisposing factors for traumatic dental injuries in Brazilian preschool children. Eur J Paediatr Dent 2010;11:59-65.

4. Wendt FP, Torriani DD, Assunção MC, Romano AR, Bonow ML, da Costa CT, et al.. Traumatic dental injuries in primary dentition: Epidemiological study among preschool children in South Brazil. Dent Traumatol 2010;26:I68-173.

5. Robson F, Ramos-Jorge ML, Bendo CB, Vale MP, Paiva SM, Pordeus IA. Prevalence and determining factors of traumatic injuries to primary teeth in preschool children. Dent Traumatol 2009;25:118-122.

6. Martins VM, Sousa RV, Rocha ES, Leite RB, Paiva SM, Granville-Garcia AF. Dental trauma among Brazilian schoolchildren: prevalence, treatment and associated factors. Eur Arch Paediatr Dent 2012;13:232-
237.

7. Cardoso M, de Carvalho Rocha MJ. Traumatized primary teeth in children assisted at the Federal University of Santa Catarina, Brazil. Dent Traumatol 2002;18:129-133.

8. Lam $\mathrm{R}$, Abbott $\mathrm{P}$, Lloyd $\mathrm{C}$, Lloyd $\mathrm{C}$, Kruger $\mathrm{E}$, Tennant M. Dental trauma in an Australian rural centre. Dent Traumatol 2008;24:663-670.

9. Brazilian Institute of Geography and Statistics, The (IBGE): Preliminary results of the 2010 population-based census. http://www.censo2010. ibge.gov.br/dadosdivulgados/index.php?uf=25, 2012

10. Burden, D. J. An investigation of the association between overjet size, lip coverage, and traumatic injury to maxillary incisors. Eur J Orthod 1995;17:513-517.

11. Grabowski R, Stahl F, Gaebel M, Kundt G. Relationship between occlusal findings and orofacial myofunctional status in primary and mixed dentition. Part I: Prevalence of malocclusions. J Orofac Orthop 2007;68:26-37.

12. WHO - World Health Organization: Oral Health Surveys. Basic Methods, 1997.

13. Andreasen JO, Andreasen FM, Andersson L. Textbook and color atlas of traumatic injuries to the teeth. $4^{\mathrm{a}}$ ed. Copenhagen: Munskgaard International Publishers; 2007.

14. Ismail Al, Sohn W, Tellez M, Amaya A, Sen A, Hasson H, et al.. The International Caries Detection and Assessment System (ICDAS): an integrated system for measuring dental caries. Community Dent Oral Epidemiol 2007;35:170-178.

15. WHO-World Health Organization: AnthroPlus for personal computers Manual: Software for assessing growth of the world's children and adolescents. http://www.who.int/growthref/tools/en/, 2012.

16. Al-Majed I, Murray JJ, Maguire A. Prevalence of dental trauma in 5-6- and 12-14-year-old boys in Riyadh, Saudi Arabia. Dent Traumatol $2001 ; 17: 153-158$.

17. Avsar A, Topaloglu B. Traumatic tooth injuries to primary teeth of children aged 0-3 years. Dent Traumatol 2009;25:323-327.

18. Grabowski R, Self S. Mother's autonomy: impact on the quality of children's healthcare in India. Applied Economics 2013;45:1903-1913.

19. Goettems ML, Azevedo MS, Correa MB, Costa CT, Wendt FP, Schuch HS, et al.. Dental trauma occurrence and occlusal characteristics in Brazilian preschool children. Pediatr Dent 2012;34:104-107.

20. Orton $E$, Kendrick D, West J, Tata $\sqcup$. Independent risk factors for injury in pre-school children: three population-based nested case-control studies using routine primary care data. PLoS One 2012;7:e35193.

21. Bonini GC, Bönecker M, Braga MM, Mendes FM. Combined effect of anterior malocclusion and inadequate lip coverage on dental trauma in primary teeth. Dent Traumatol 2012;28:437-440.

22. Petti S, Cairella G, Tarsitan G. Childhood obesity: a risk factor for traumatic injuries to anterior teeth. Endod Dent Traumatol 1997;13:285-288.

23. Mestrinho HD, Bezerra AC, Carvalho JC. Traumatic dental injuries in Brazilian pre-school children. Braz Dent J 1998;9:101-104.

24. Self $S$, Grabowski R. Female Autonomy and health care in developing countries. Review of Development Economics 2012;16:185-198.

25. Camargo MBJ, Barros AJD, Frazão P, Matijasevich A, Santos IS, Peres MA et al. Predictors of dental visits for routine check-ups and for the resolution of problems among preschool children. Rev Saude Publica 2012;46:87-97. 